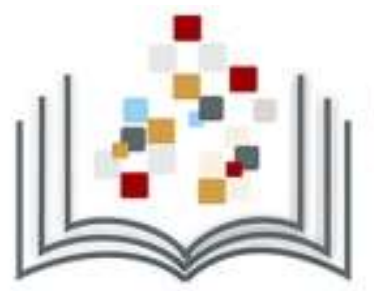

\title{
POLÍTICA DE USO DE REDES SOCIAIS E PERIÓDICOS CIENTÍFICOS: A EXPERIÊNCIA DA REVISTA BRASILEIRA DE EDUCAÇÃO FÍSICA E ESPORTE
}

Solange Alves Santana ${ }^{1^{*}}$

1Universidade de São Paulo - Escola de Educação Física e Esporte - São Pulo (SP) Brasil

*Autor correspondente: solangeusp@gmail.com

\section{Como citar:}

Santana, Solange A.. Política de uso de redes sociais e periódicos científicos: a experiência da revista brasileira de educação física e esporte. In: WORKSHOP DE EDITORAÇÃO

CIENTÍFICA, 9., 2016, São Paulo. Anais... São Paulo: Associação Brasileira de Editores

Científicos, 2016. p. 60-64

DOI: http://dx.doi.org/10.21452/wec.IXwec.2016.0012

\section{RESUMO}

O trabalho relata a experiência da equipe editorial da Revista Brasileira de Educação Física e Esporte (RBEFE) na elaboração e implementação da política de uso das redes sociais.

\section{INTRODUÇÃO}

As redes sociais online se configuram como um espaço ampliado para interação, comunicação e sociabilidade e, nos últimos anos, vem ocupando um espaço crescente no meio científico-acadêmico, favorecendo ações relacionadas à comunicação e divulgação da ciência. Concomitantemente, a presença de periódicos científicos tem se intensificado no universo das redes sociais, potencializando e amplificando o espaço comunicacional das publicações. Packer (2013), afirma que "as redes sociais se projetam no futuro próximo como o principal meio de divulgação para os periódicos científicos". No entanto, Nassi-Calò (2015) aponta que:

[...] apesar do crescente interesse da comunidade acadêmica nas redes sociais como ferramenta de comunicação científica, pouco se sabe a respeito do perfil de uso destas ferramentas, e sobre como medidas tradicionais de impacto científico com base em citações (índices off-line, impacto off-line) se correlacionam com as novas medidas de impacto (índices online, impacto online).

No Brasil, ainda são incipientes os estudos sobre a presença de periódicos científicos nas redes sociais, bem como sobre a utilização dessas ferramentas como canais de comunicação entre periódico/leitor e vice-versa. Desse modo, iniciativas como dos blogs Divulga Ciência ${ }^{1}$, Scientific Electronic Library Online (SciELO) em perspectiva $^{2}$ e da Associação Brasileira de Editores Científicos (ABEC) ${ }^{3}$ têm se configurado como espaços catalisadores no fomento de discussões $e$ compartilhamento de experiências acerca da incursão dos periódicos nas redes e mídias sociais.

\footnotetext{
${ }^{1}$ Disponível em: https://blogdivulgaciencia.wordpress.com

${ }^{2}$ Disponível em http://blog.scielo.org/

${ }^{3}$ Disponível em: www.abecbrasil.org.br
} 
Diante desse cenário, o presente trabalho objetiva apresentar a experiência da equipe editorial da Revista Brasileira de Educação Física e Esporte (RBEFE) na elaboração e implementação da política de uso das redes sociais.

\section{POLÍTICAS DE USO DE REDES SOCIAIS E PERIÓDICOS CIENTÍFICOS}

Devemos considerar que a criação de perfis e páginas em redes sociais é um procedimento relativamente simples, dada as facilidades disponibilizadas, como navegação intuitiva, geração automática de indicadores, etc. No entanto, assim como qualquer atividade editorial, a incursão nas redes sociais requer planejamento, a fim de permitir o uso eficiente e qualificado dessas ferramentas, uma vez que novas tarefas e novos atores passarão a fazer parte da rotina da equipe editorial.

Em artigo sobre os desafios dos editores científicos nas redes sociais, Benchimol, Cerqueira e Papi (2014, p. 362) apontam que:

As novas personas do periódico nas redes sociais atraíram público muito mais vasto e diversificado do que aquele que efetivamente lê os trabalhos da revista e os utiliza como matéria-prima para novas produções analíticas ou docentes. Em que medida essa gente nova que lê e curte HCS - Manguinhos redundará em melhor desempenho acadêmico da revista? Não se sabe ainda.

De fato, a incursão dos periódicos nas redes sociais trazem desafios, demandas e perspectivas distintos daqueles comuns às atividades tradicionalmente editoriais e, nesse sentido, é necessário que a equipe editorial se estruture de forma a se adequar ao novo contexto. Uma das ações que envolvem a adequação ao trabalho com as redes sociais é a definição e implementação de uma política de uso das redes sociais. As políticas de uso visam direcionar e pautar as atividades relacionadas ao gerenciamento, práticas, estratégias de comunicação e monitoramento das redes.

\section{A RBEFE E AS REDES SOCIAIS}

Visando alinhar-se às demandas e tendências de divulgação científica e disponibilização do conhecimento, em 2012, a equipe editorial da RBEFE criou perfis do períodico nas redes sociais Facebook, LinkedIn, Mendeley, Pinterest, SlideShare e Twitter (Quadro 1).

Quadro 1: Características das redes sociais e dos perfis da RBEFE Fonte: A autora. São Paulo, 2016.

\begin{tabular}{|c|c|c|}
\hline $\begin{array}{l}\text { Rede } \\
\text { social }\end{array}$ & Características & Características do perfil da RBEFE \\
\hline Facebook & $\begin{array}{l}\text { Lançada em } 2004 \text {, a rede social } \\
\text { permite criar perfis pessoais ou } \\
\text { páginas como empresa, figura } \\
\text { pública, marca, comunidade, } \\
\text { entre outros. Permite também } \\
\text { elaborar enquetes, usar } \\
\text { aplicativos, entre outros } \\
\text { serviços. }\end{array}$ & $\begin{array}{l}\text { São divulgadas informações sobre a revista, } \\
\text { sobre novos fascículos e artigos disponíveis } \\
\text { em 'ahead of print'. Fornece dicas de leituras } \\
\text { (artigos publicados em anos anteriores na } \\
\text { RBEFE), dicas sobre redação científica e } \\
\text { gerenciadores de referências e divulga } \\
\text { eventos da área. } \\
\text { O perfil está disponível em: } \\
\text { http://facebook.com/reveefe. }\end{array}$ \\
\hline
\end{tabular}




\begin{tabular}{|c|c|c|}
\hline Linkedln & $\begin{array}{l}\text { Lançado oficialmente em } 2003 \text {, } \\
\text { o objetivo do site é reunir } \\
\text { profissionais, através de listas } \\
\text { de contatos (pessoas ou } \\
\text { empresas), promovendo a } \\
\text { interatividade entre profissionais } \\
\text { e a prática de networking. }\end{array}$ & $\begin{array}{l}\text { A divulgação de conteúdo da RBEFE no } \\
\text { Linkedln segue a mesma proposta } \\
\text { estabelecida para o Facebook. } \\
\text { O perfil está disponível em: } \\
\text { http://br.linkedin.com/in/rbefe. }\end{array}$ \\
\hline Mendeley & $\begin{array}{l}\text { Lançado em 2008, é um } \\
\text { gerenciador gratuito de } \\
\text { referências. Possui duas } \\
\text { versões integradas, desktop e } \\
\text { web, que permitem a pesquisa, } \\
\text { o compartilhamento de arquivos, } \\
\text { a organização de referências de } \\
\text { acordo com normas nacionais e } \\
\text { internacionais. Apresenta } \\
\text { recursos de rede social como } \\
\text { mural de mensagens, listas de } \\
\text { contatos e interesses } \\
\text { profissionais e definição de } \\
\text { níveis de privacidade. }\end{array}$ & $\begin{array}{l}\text { O perfil da RBEFE no Mendeley possui uma } \\
\text { biblioteca com as referências de todo o } \\
\text { conteúdo publicado pela revista, fornecendo o } \\
\text { link para acesso ao texto completo nos Portais } \\
\text { SciElo ou Revistas USP. Deste modo, busca- } \\
\text { se alimentar a base de artigos do Mendeley e } \\
\text { facilitar o processo de citação dos artigos } \\
\text { publicados. } \\
\text { O perfil está disponível em: } \\
\text { http://www.mendeley.com/profiles/rbefe-usp. }\end{array}$ \\
\hline Pinterest & $\begin{array}{l}\text { Lançado em 2010, é uma rede } \\
\text { social que permite ao usuário } \\
\text { criar e compartilhar painéis } \\
\text { (quadros virtuais de imagens, } \\
\text { fotos e vídeos). Assim como no } \\
\text { Twitter, os usuários seguem uns } \\
\text { aos outros e o conteúdo de } \\
\text { quem você segue aparece em } \\
\text { sua página inicial. No entanto, } \\
\text { no Pinterest há a possibilidade } \\
\text { de seguir apenas painéis de seu } \\
\text { interesse. }\end{array}$ & $\begin{array}{l}\text { O perfil da RBEFE disponibiliza murais } \\
\text { temáticos nas áreas de Biodinâmica, } \\
\text { Sociocultural e Pedagogia e Eventos. } \\
\text { O perfil está disponível em: } \\
\text { http://pinterest.com/rbefe. }\end{array}$ \\
\hline SlideShare & $\begin{array}{l}\text { Lançado em 2006, é uma } \\
\text { ferramenta gratuita para } \\
\text { compartilhamento de } \\
\text { apresentações em Power Point, } \\
\text { Pdf ou similares. Possui } \\
\text { fermentas de busca e permite a } \\
\text { classificação das apresentações } \\
\text { por meio de tags e a adição de } \\
\text { comentários. As apresentações } \\
\text { podem ser compartilhadas } \\
\text { através de e-mail ou página web } \\
\text { ou ainda por meio de downloads } \\
\text { quando permitidos. }\end{array}$ & $\begin{array}{l}\text { O perfil da RBEFE no SlideShare disponibiliza } \\
\text { as "Instruções aos autores", dados estatísticos } \\
\text { da revista e tutoriais para o uso de } \\
\text { ferramentas online, como Endnote Web, } \\
\text { Mendeley e Pinterest. } \\
\text { O perfil está disponível em: } \\
\text { http://www.slideshare.net/RBEFE. }\end{array}$ \\
\hline Twitter & $\begin{array}{c}\text { Serviço de microblogging criado } \\
\text { em } 2006 . \text { Permite publicar } \\
\text { textos de até } 140 \text { caracteres, } \\
\text { fotos e links. }\end{array}$ & $\begin{array}{c}\text { É priorizada a divulgação de notícias } \\
\text { relacionadas à área de Educação Física e } \\
\text { sobre o universo dos periódicos científicos. } \\
\text { O perfil está disponível em: } \\
\text { http://twitter.com/rbefe. }\end{array}$ \\
\hline
\end{tabular}


O projeto de criação dos perfis nas redes sociais foi estabelecido no planejamento estratégico anual da equipe editorial da RBEFE, sendo definidas ações prévias para direcionar o trabalho. As ações previstas foram: (i) estudo do público-alvo do periódico por meio de questionário enviado a autores, editores, assinantes e pesquisadores da área de Educação Física e Esporte com questões referentes ao uso de redes sociais no âmbito científico-acadêmico; (ii) análise de perfis e práticas de periódicos científicos brasileiros e estrangeiros em redes sociais (benchmarking); (iii) levantamento de boas práticas e políticas de periódicos voltadas para redes socais; (iv) elaboração do manual "Política de uso das mídias sociais da Revista Brasileira de Educação Física e

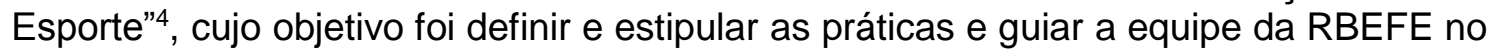
uso das redes sociais, incluindo geração de conteúdo, interação com o usuário e atuação em caso de crise.

\section{ELABORAÇÃO DA POLÍTICA PARA REDES}

A elaboração de uma política de uso de redes sociais deve preocupar-se em orientar e tratar adequadamente os diferentes aspectos envolvidos na comuniçação no ambiente web, levando em consideração impactos à reputação do periódico. É preciso destacar que a definição de uma política de uso de redes sociais deve estar alinhada ao perfil e ao contexto de inserção do periódico, bem como deve alinhar-se ao perfil de seu público e às características próprias de cada rede social.

$\mathrm{Na}$ política de uso das redes sociais da RBEFE foram definidas as diretrizes norteadoras no que diz respeito a: (a) público; (b) objetivo dos perfis; (c) procedimentos para gestão; (d) conteúdo e frequência das postagens; (e) redação e linguagem; (f) relacionamento com o usuário; (g) moderação; (h) gerenciamento de crise; (i) utilização de textos e imagens; (j) monitoramento das redes.

Cabe destacar que na elaboração da política os itens não devem ser tomados isoladamente, mas sim, contextualizados e inter-relacionados.

No que diz respeito ao público, verificou-se por meio do levantamento realizado que o público do periódico possui idade média entre 30-40 anos (35\%), possuem pósgraduação $(40 \%)$, composto majoritariamente por mulheres $(53 \%)$ e presentes em redes sociais $(72 \%)$. O levantamento desses dados permitiu, por exemplo, direcionar tom da linguagem a ser adotada nas redes. Cabe ressaltar que os indicadores fornecidos posteriormente pelas redes sociais corroboram os dados obtidos no levantamento inicial.

Quanto aos objetivos dos perfis, houve a preocupação em não sobrepor assuntos, para que, desse modo, não houvesse a replicação de conteúdos reiteradamente e cada perfil apresentasse sua identidade. Assim, a política fornece diretrizes sobre o tipo de conteúdo e a linguagem apropriada em cada perfil.

A indicação dos procedimentos de gestão, relacionamento com o usuário, moderação, frequência das postagens também são itens inter-relacionados, e sua definição na política permite que qualquer membro da equipe editorial compreenda como as redes sociais devem ser geridas.

Como toda política editorial, é preciso também considerar a necessidade revisar e atualizar continuamente a política de uso nas redes sociais, dado o caráter dinâmico das redes (BARATA, 2015). Também cabe destacar a necessidade de orientação da equipe para a moderação nas redes sociais, a fim de desenvolver estratégias eficazes de comunicação.

\section{CONSIDERAÇÕES FINAIS}

A definição e implementação de uma política de uso para redes socais subsidiam e fundamentam o trabalho das equipes editoriais, evitando que as redes sejam postas em segundo plano na rotina e, consequentemente, percam o caráter

${ }^{4}$ Disponível em: http://pt.slideshare.net/RBEFE/polticas-de-uso-das-mdias-sociais-da-rbefe-2012 
dinâmico que as redes sociais exigem. Cabe ressaltar também que o estabelecimento de uma política não é engessar as práticas e ações das equipes editoriais, nortear o trabalho. Nesse viés, ressaltamos a necessidade de rever e revisar as políticas periodicamente, haja vista a dinamicidade das redes.

A criação dos perfis da RBEFE nas redes sociais trouxe novas perspectivas de abertura de espaços de interação e convergência entre autores, editores e usuários pode contribuir para a inserção de novos atores no fluxo de comunicação científica, promovendo a utilização ampla de resultados das pesquisas e estudos científicos.

\section{REFERÊNCIAS}

BARATA, Germana. Revista científica publica manual de política de uso de redes sociais. 2015. Disponível em:

$<$ https://blogdivulgaciencia.wordpress.com/2015/08/31/revista-cientifica-publicamanual-de-politica-de-uso-de-redes-sociais/>. Acesso em: 5 de out. 2016.

BENCHIMOL, Jaime L.; CERQUEIRA, Roberta C.; PAPI, Camilo. Desafios aos editores da área de humanidades no periodismo científico e nas redes sociais: reflexões e experiências. Educação e Pesquisa, [s.I.], v. 40, n. 2, p.347-364, maio 2014. FapUNIFESP (SciELO). http://dx.doi.org/10.1590/s1517-97022014061668.

NASSI-CALÒ, Lilian. Estudo analisa o uso de redes sociais na avaliação do impacto científico. 2015. SciELO em Perspectiva. Disponível em:

$<$ http://blog.scielo.org/blog/2015/03/13/estudo-analisa-o-uso-de-redes-sociais-naavaliacao-do-impacto-cientifico/\#.WEScCdIrLIU>. Acesso em: 5 out. 2016.

PACKER, Abel. Redes sociais para divulgar ciência. História, Ciências, Saúde Manguinhos. 2013. Disponível em: <http://www.revistahcsm.coc.fiocruz.br/redessociais-para-divulgar-ciencia/>. Acesso em: 7 de out 2016

PALAVRAS-CHAVE: Periódicos científicos. Redes sociais. Boas práticas. 